Article

\title{
Optimizing Food Waste Composting Parameters and Evaluating Heat Generation
}

\author{
Chin Ko Yeh ${ }^{1}$, Chitsan Lin ${ }^{1,2, *}$, Hsueh Chen Shen ${ }^{1}$, Nicholas Kiprotich Cheruiyot ${ }^{2}$, \\ Mary Ellen Camarillo ${ }^{3}{ }^{(1)}$ and Chung Lung Wang ${ }^{2}$ \\ 1 College of Maritime Science and Technology, National Kaohsiung University of Science and Technology, \\ Kaohsiung 81157, Taiwan; chinko@nkust.edu.tw (C.K.Y.); hsuehchen@nkust.edu.tw (H.C.S.) \\ 2 Department of Marine Environmental Engineering, National Kaohsiung University of Science and \\ Technology, Kaohsiung 81157, Taiwan; kipnichols26@nkust.edu.tw (N.K.C.); \\ deavewang@gmail.com (C.L.W.) \\ 3 Engineering Graduate Program, School of Engineering, University of San Carlos, Cebu City 6000, \\ Philippines; maryellencamarillo@gmail.com \\ * Correspondence: ctlin@nkust.edu.tw; Tel.: +866-7-3617141; Fax: +886-7-3651472
}

Received: 25 February 2020; Accepted: 23 March 2020; Published: 27 March 2020

Featured Application: This study shows the potential of heat production from food waste composting and lays the foundation for future heat recovery studies.

\begin{abstract}
The optimal initial moisture content and seeding proportion with mature compost (microbial inoculant) during food waste composting were investigated. This involved six different moisture contents $(42 \%, 55 \%, 61 \%, 66 \%, 70 \%$, and $78 \%$ ) and four different mature compost seeding amounts $(0 \%, 10 \%, 20 \%$, and $30 \% w / w)$. The temperature variation of these different setups during the first four days of composting was used to determine the most effective one. Our findings showed that the initial moisture contents of $55-70 \%$ and the $20 \% w / w$ of mature compost were optimal for effective food waste composting. A $400 \mathrm{~kg}$ compost pile with the optimal compost mixture ratio was then used to study the evolution and spatial distribution of the temperature during a 30-day composting period. Finally, the heat produced during the 30-day composting process was estimated to be $2.99 \mathrm{MJ} / \mathrm{kg}$. Further investigations, including a cost-benefit analysis from a pilot facility, would be required to comprehensively conclude the feasibility of food waste composting as a bioenergy source.
\end{abstract}

Keywords: facultative aerobic treatment; moisture content; microbial inoculant; bioenergy recovery; waste-to-resource

\section{Introduction}

Food waste from restaurants, markets, and households, especially in high-density regions, presents a waste management challenge as well as a waste-to-resource opportunity [1]. This waste can be used in a variety of ways, such as for livestock feed [2], for biogas generation [3], to synthesize chemicals [4-6], and for composting $[7,8]$. However, if improperly disposed of, food waste might lead to foul smells, greenhouse gas emissions, and even food and habitats for vector organisms, including rats, cockroaches, and houseflies $[9,10]$. Composting is one of the most cost-effective and environmentally friendly technologies for managing food waste [11,12].

Composting is a biochemical process that biodegrades and converts food waste into a humus-like substance that can be used as a fertilizer and soil enhancer [7]. Therefore, this technology also transforms waste into a resource that can be utilized by farmers, in cities' green spaces, and by gardening enthusiasts $[13,14]$. Apart from food waste, a typical food waste composting system would also consist of a bulking agent and a microbial inoculant [15]. Bulking agents, such as sawdust and 
cereal plant straws, are used to control the initial moisture content and adjust the $\mathrm{C} / \mathrm{N}$ ratio of the composting mixture $[16,17]$. The common bulking agents, being more ligninous in nature compared to the food waste, also provide structure to the mixture, which enhances the flow of air within the compost, and thereby promotes aerobic biodegradation [16]. A microbial inoculant, such as mature compost, is used to enrich the compost with the vital microbial communities required for the biotransformation of food waste $[18,19]$. In addition, parameters including moisture and turning frequency/aeration rate of the compost mixture are of vital importance for effective composting [20,21]. For instance, a dry compost mixture would inhibit nutrient mobility, while a very wet mixture would hinder oxygen penetration, leading to anoxic conditions [21]. These two extreme moisture conditions would result in lower aerobic microbe activities and negatively affect the composting process. The accepted moisture content range for effective composting is $40-65 \%$ [21].

The composting process is exothermic, where heat is released as a result of the biodegradation of the food waste by aerobic microbes [22]. The heat is mostly produced during the thermophilic phase, where the temperatures of the compost pile could be as high as $>70^{\circ} \mathrm{C}$ [23]. Few researchers have calculated the heat produced and their results greatly varied, which could be because of the diverse biomass and composting methods used in those studies [22,24]. For example, Ahn, Richard, and Choi [22] calculated the heat generated from composting a mixture of poultry and wood shavings during the thermophilic phase to be 16.83 to $19.7 \mathrm{MJ} / \mathrm{kg}$. Thus, the heat from the composting process has the potential to be captured and utilized in several applications including water heating. However, the heat recovery from composting varies depending on the composting method, composting mixture, type of loading, composting scale, the heat exchange system, basis for the operational data, geographical location, and heat recovery duration [25,26]. Smith, Aber, and Rynk [25] reviewed 45 composting heat recovery systems and reported that the average recovery rates were 1159, 4302, and $7084 \mathrm{~kJ} / \mathrm{kg}$ dry mass of compost feedstock for lab-scale, pilot-scale, and commercial-scale composting systems, respectively.

Therefore, the objective of this study is to determine the optimal initial moisture content and amount of mature compost to be added to the compost mixture. Six initial moisture contents $(42 \%, 55 \%$, $61 \%, 66 \%, 70 \%$ and $78 \%$ ) and four mature compost ratios $(0 \%, 10 \%, 20 \%$, and $30 \% w / w)$ were investigated. In addition, an attempt was made to estimate the heat that can be produced from a $400 \mathrm{~kg}$ compost pile after a 30-day composting process. The results from this study will add to the research field on bioenergy.

\section{Materials and Methods}

The study was carried out at a compost facility located at the National Kaohsiung University of Science and Technology in Kaohsiung, Taiwan. The compost facility was in a double-span greenhouse that covers an area of around $100 \mathrm{~m}^{2}$ and has a maximum height of $7 \mathrm{~m}$. The composting materials consisted of food waste, sawdust (bulking agent), and mature compost (microbial inoculant). The food waste was collected from food establishments and households near to the university; the sawdust was purchased; and the mature compost was sourced from the compost facility.

Uncovered $150 \mathrm{~kg}$ cone-shaped compost piles were used to study the optimal initial moisture content and mature compost proportion during the food waste composting. The piles had base diameters of $\sim 1.2 \mathrm{~m}$ and heights of $0.6-0.8 \mathrm{~m}$. Six compost piles from the same batch with different initial moisture contents $(42 \%, 55 \%, 61 \%, 66 \%, 70 \%$ and $78 \%)$ were investigated. The initial moisture content was achieved by spreading the food waste on a mesh filter and air drying overnight, as well as adding different amounts of water. In addition, four compost piles with different mature compost ratios $(0 \%, 10 \%, 20 \%$, and $30 \% w / w)$ were studied to determine the optimal seeding proportion. The moisture content of the piles was maintained at $60-65 \%$.

Thereafter, a $400 \mathrm{~kg}$ compost pile with the optimal initial moisture content and mature compost proportion was set up to study the temperature, moisture, and $\mathrm{pH}$ of the compost mixture during a 30-day incubation period. The pile had a base diameter of $\sim 1.70 \mathrm{~m}$ and a height of $0.7-1.0 \mathrm{~m}$. The compost experiments were set up similarly to our previous study [15]. Prior to mixing the 
composting materials, the food waste was ground to sizes $<2 \mathrm{~cm}$ before the sawdust was added to adjust the moisture content. The mature compost was then applied to ensure that the compost contained adequate microbes for an effective composting operation. Finally, the initial composting material was homogeneously mixed and stacked in cone-shaped piles for easy aeration and parameter control. The compost piles were incubated for 30 days during which the temperature, moisture content, and $\mathrm{pH}$ were monitored daily. The piles were turned over daily using shovels to ensure aerobic conditions were maintained.

Before the daily turnover, the surface of the $400 \mathrm{~kg}$ pile was divided into ca. $15 \times 15 \mathrm{~cm}$ patches, and the temperature within each was recorded using a digital thermometer (TES $1310 \mathrm{~K}$-type) with $\pm 0.1^{\circ} \mathrm{C}$ sensitivity furnished in a $1.2 \mathrm{~m}$ probe. This facilitated about 50 measurements. The coordinates and the temperature readings were then plotted into $2 \mathrm{D}$ temperature contour plots using Surfer $\AA$ version 15. Compost samples were also collected daily at five different points of the pile (from the center and at four equidistant points, $15-20 \mathrm{~cm}$ deep) for the analysis of the moisture and $\mathrm{pH}$. The samples were homogeneously mixed before the analysis. The moisture content was determined following the NIEA R203.02C Taiwan standards, while the $\mathrm{pH}$ analysis followed the USEPA method 9045C. The C:N ratio was measured using the NIEA R.409.21C standard method.

\section{Results and Discussion}

\subsection{Optimal Moisture Content and Mature Compost Seeding Amount for Effective Composting}

The six initial moisture contents were plotted against the temperature during the first four days of composting, as shown in Figure 1a. The composting setups with the initial moisture contents of $55-70 \%$ had the highest temperature-increasing rates $\left(5.7-5.8^{\circ} \mathrm{C} /\right.$ day $)$, while the setups with the initial moisture contents of $42 \%$ and $78 \%$ had the lowest temperature-increasing rates of 2.4 and $2.7^{\circ} \mathrm{C} /$ day, respectively. The increase in the compost temperature is an indicator of microbial activity during the composting period [27]. The beginning of the composting period is usually characterized by a dramatic increase in the temperature generated from the aerobic breakdown of the organic matter by the microbial communities present within the compost mixture [28]. A lower moisture content inhibits the microbial activity by hindering the nutrient mobility within the pile. This leads to lower temperature increases [21]. A higher moisture content leads to poor oxygen penetration being required by the aerobic microbes, and thus reduces their activity and shifts biodegradation towards more anoxic conditions which favor the anaerobic microbes [29]. Liang et al. [30] indicated that a 50\% moisture content is the minimal requirement for facilitating these microbial activities. From our results, the optimal initial moisture contents of $55-70 \%$ were found to be effective for the optimal food waste composting operations.

Mature compost was added to the compost mixture as an inoculant, thereby enriching the microbial communities within the compost pile. Due to its low moisture content, mature compost can also be used to reduce the total moisture content of the composting mixture [31]. Figure $1 \mathrm{~b}$ shows the temperature trend of the four setups $(0 \%, 10 \%, 20 \%$ and $30 \% w / w)$ during the first four days of the composting period. From day 0 to day 1 , the temperature increased to more than $45^{\circ} \mathrm{C}$ for all the four setups. A clear difference among the setups started to emerge after the first day. The $0 \%$ setup, which did not have any mature compost addition, had the lowest temperature increase. This could be because of the lower microbial population compared to the other setups, indicating that the microbial population plays an important role in the temperature increase during incubation [32]. The highest temperature increase was observed for the $20 \%$ setup. On day 2, the temperature for the $20 \%$ setup rose to more than $70{ }^{\circ} \mathrm{C}$, which was higher than all the other setups, and reached $73^{\circ} \mathrm{C}$ on day 3 . The seeding proportion of the $30 \%$ mature compost did not result in a higher temperature increase. This phenomenon was probably because of a reduction in the initial moisture of the compost mixture caused by the addition of the mature compost, which had a moisture content of only $20 \%$. Our results indicated that seeding the compost mixture with the $20 \%$ mature compost was optimal for an effective 
composting process. However, it should also be noted that by day 4 , there was not much difference between the setups, apart from the $0 \%$ setup.
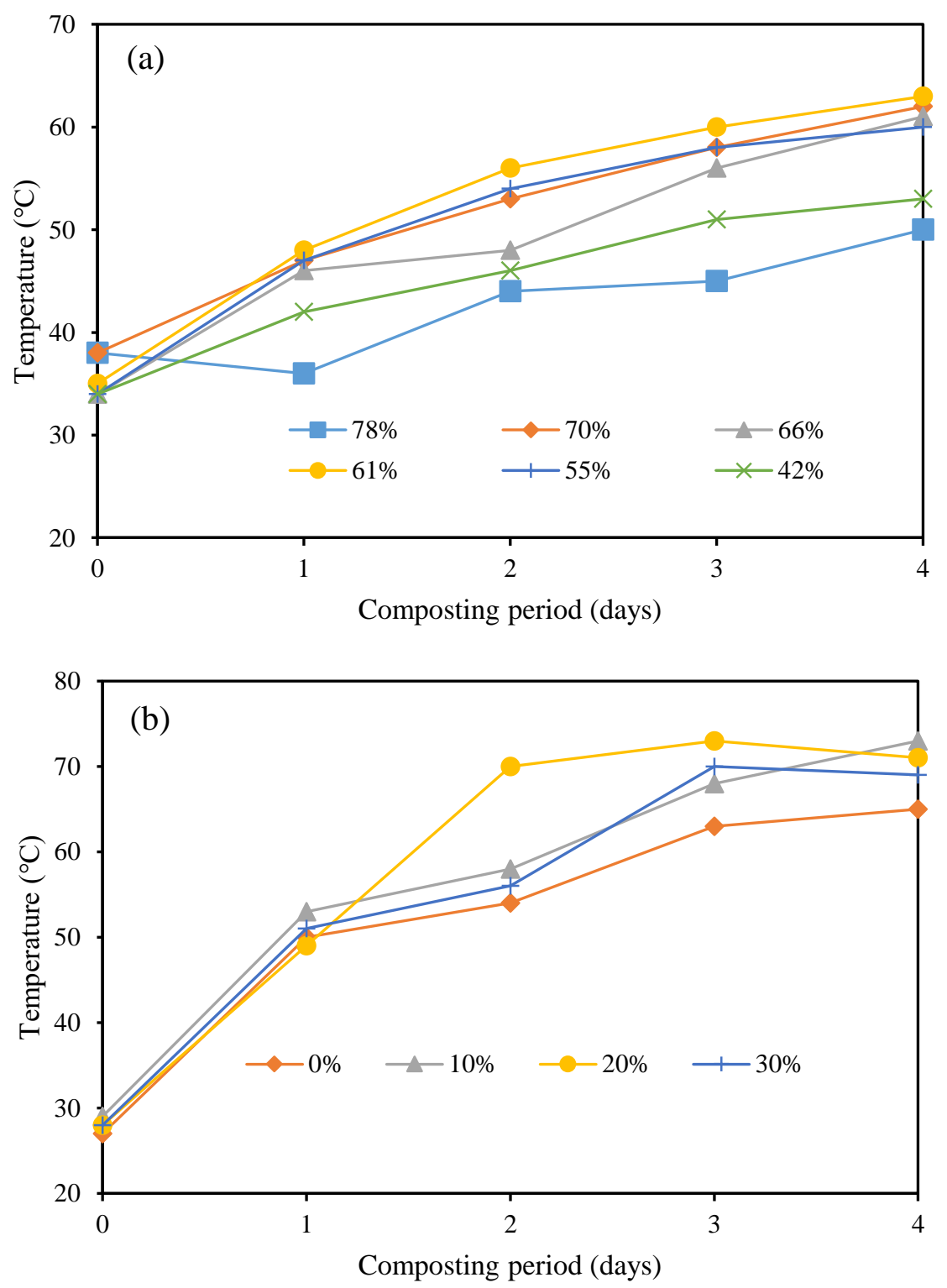

Figure 1. Temperature development influenced by (a) initial moisture content and (b) seeding proportions.

\subsection{Moisture Content, Temperature, and pH Variation during a 30-Day Composting Period}

A compost pile with the optimal initial moisture content and mature compost seeding amount identified in Section 3.1 was used to study the moisture content, temperature, and $\mathrm{pH}$ variation during the entire composting process. The physicochemical properties of the compost mixture are presented in Table 1.

Figure 2 shows the moisture content variation during the composting period. The initial moisture content was $65 \%$, which was within the optimal range of $55-70 \%$ for the food waste reported in this study. At this optimal range, the pile was not too dry or too wet for the microbial communities to thrive. For instance, sawdust was added initially to reduce the high moisture content of the food waste, and water was added during the thermophilic stage, where water loss occurs via evaporation. The moisture content was maintained at 45-65\% throughout the entire process, as shown in Figure 2; hence, the microbial community in the pile had the conditions necessary for an effective performance [21]. 
Table 1. Physicochemical characteristics of the $400 \mathrm{~kg}$ compost pile.

\begin{tabular}{lcccc}
\hline Component & Weight $\mathbf{( k g )}$ & $\mathbf{p H}$ & $\mathbf{C} / \mathbf{N}$ Ratio & Moisture Content (\%) \\
\hline $\begin{array}{l}\text { 1. Food waste (comprised of } 80 \mathrm{~kg} \\
\text { vegetable and fruit peel, 70 kg }\end{array}$ & 260 & 4.3 & 11 & 80 \\
meat and animal skin and $110 \mathrm{~kg}$ & & & & \\
cooked food) & 60 & 6.8 & 519 & 15 \\
2. Sawdust & 80 & 6.5 & 29 & 20 \\
3. Mature compost & $\mathbf{4 0 0}$ & $\mathbf{4 . 5}$ & $\mathbf{2 2}$ & $\mathbf{6 5}$ \\
\hline Initial compost mixture & & & & \\
\hline
\end{tabular}

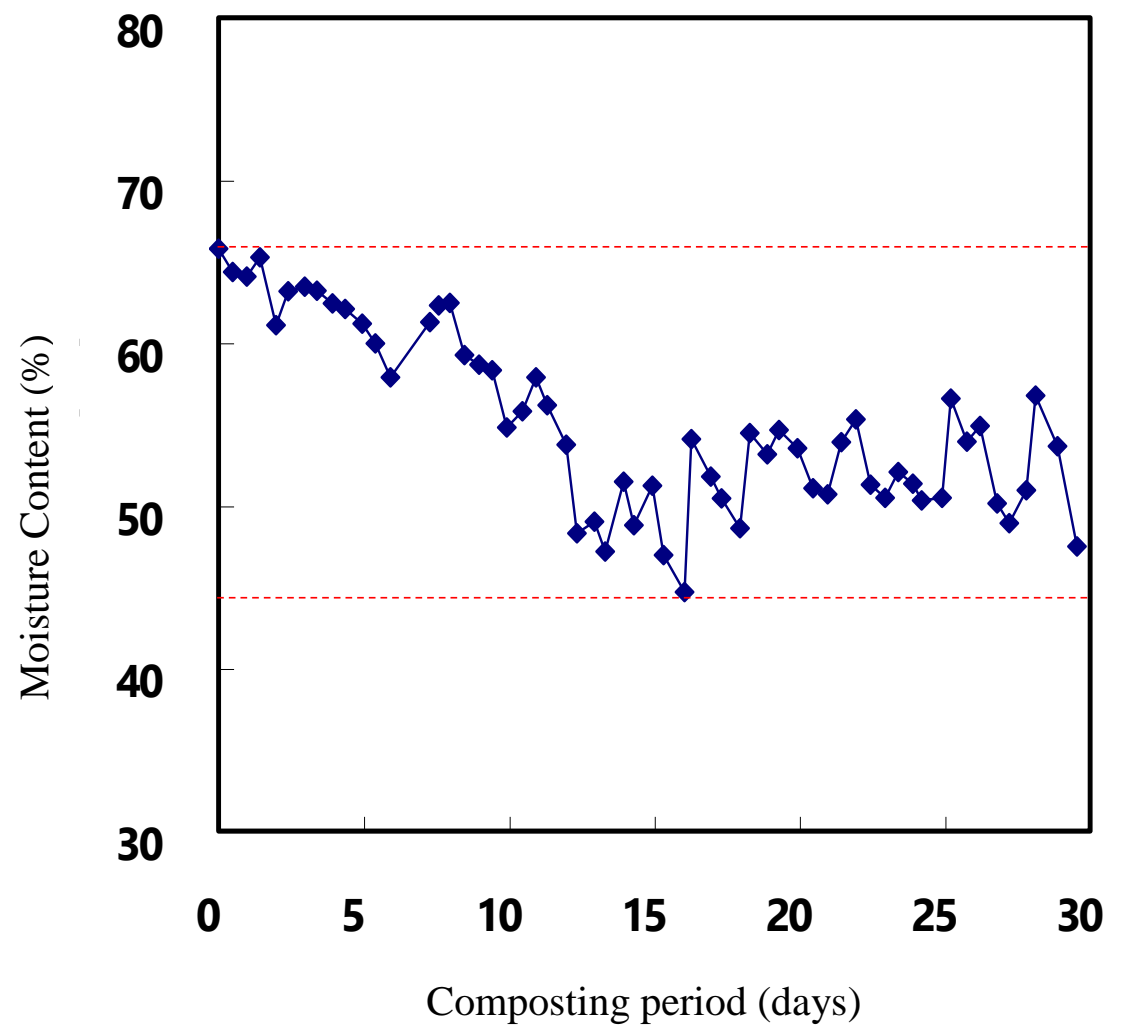

Figure 2. Moisture content variation during the composting period.

The temperature variation is presented in Figure 3. The temperature sharply rose from an ambient temperature to $50{ }^{\circ} \mathrm{C}$ after one day, then it briefly stayed steady until about day 4 . This abrupt increase in temperature is an indication of the increasing microbial activity when utilizing the compost material [28]. This phase is usually characterized by an abundance of mesophilic microorganisms [33]. However, as the temperature rose to $50^{\circ} \mathrm{C}$, the conditions became unfavorable for the mesophiles, while the thermophiles within the microbial community started to thrive [34]. This group of microbes would first need to acclimatize before growing. This was probably the reason for the observed plateauing in the temperature, as shown in Figure 3 . Thereafter, the temperature steadily rose to $70^{\circ} \mathrm{C}$ at day 7 and stayed relatively constant at $70-75^{\circ} \mathrm{C}$ until day 20 . During this thermophilic phase, the microbial activity is at its highest. However, as the nutrients diminish, the microbial activity decreases, leading to the cooling phase, where temperatures fall (days 20-25) and tend to approach the ambient temperature. The compost is said to mature when the temperature of the pile corresponds with the surrounding temperature. 


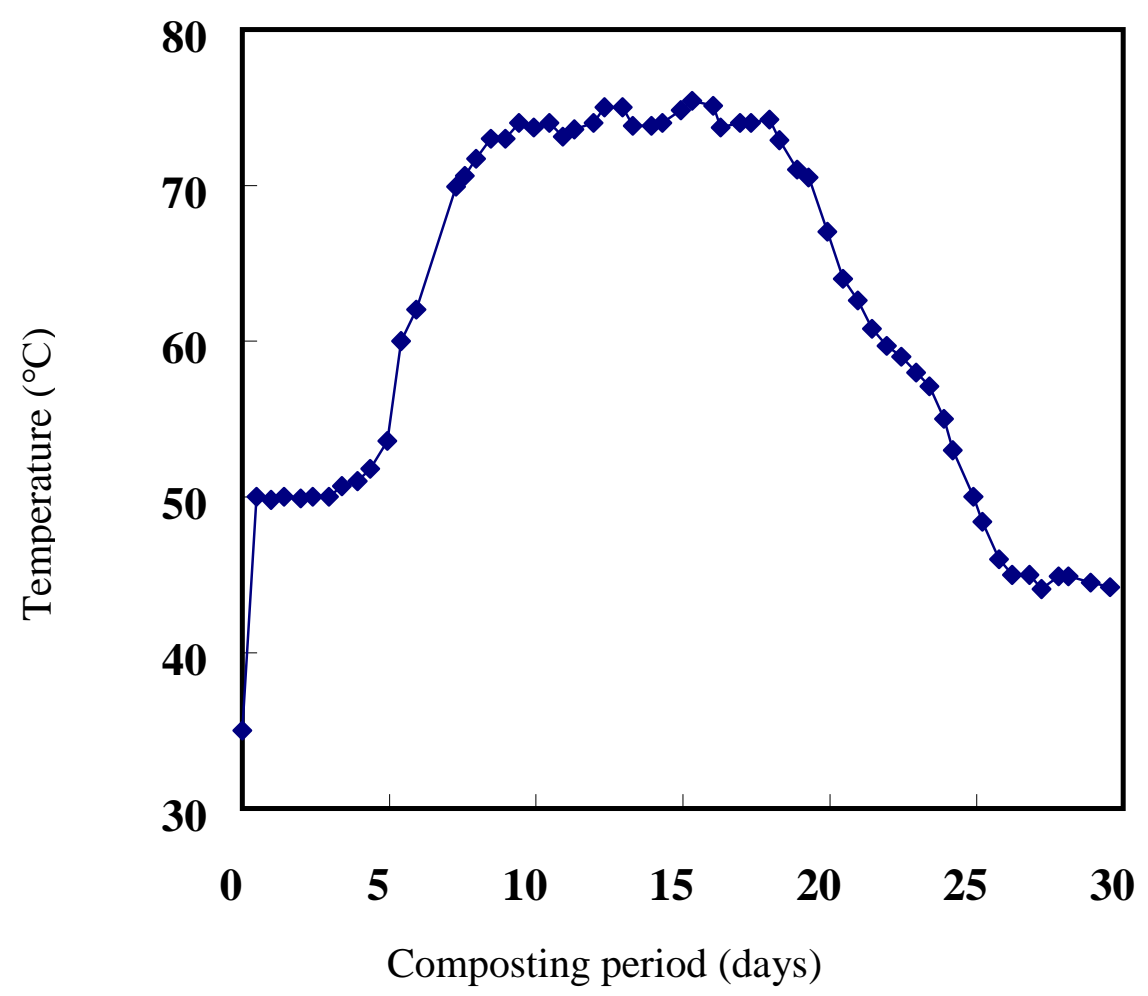

Figure 3. Temperature variation during the composting period.

Figure 4 shows the $\mathrm{pH}$ variation during the composting period. The initial composting mixture was acidic at a pH of 4.5 and the acidity further increased to 3.6 after day 1 . This observation is similar to other previous studies [35,36]. The acidity is probably due to the organic acids, such as acetic acid, that are naturally produced during the fermentation of the food waste $[35,37]$. However, the $\mathrm{pH}$ of the compost pile rises with the increasing composting period. This could be because of the vaporization of the organic acid due to the rising temperature of the pile and the turning of the pile for aeration. Most of the organic acids produced during the fermentation are volatile and the increase in compost temperature would allow them to escape into the environment as gases. $\mathrm{NH}_{3}$, a byproduct of the microbial utilization of the available nitrogen sources, will also be generated during the composting period [8]. A part of the organic acids will be neutralized by the alkaline gas. However, when the $\mathrm{pH}$ rises above 6.5, the buffering capacity of the organic acids decreases and leads to the release of $\mathrm{NH}_{3}$. This was probably the reason for the observed steady increase in the pile's $\mathrm{pH}$, as shown in Figure 4 . After the depletion of the nitrogen sources, the production of $\mathrm{NH}_{3}$ will cease and the $\mathrm{pH}$ will approach neutral. After day 20, the $\mathrm{pH}$ of the pile fluctuated within 7.0 7.5, suggesting that the nitrogen source was depleting, which slowed down the microbial activities. 


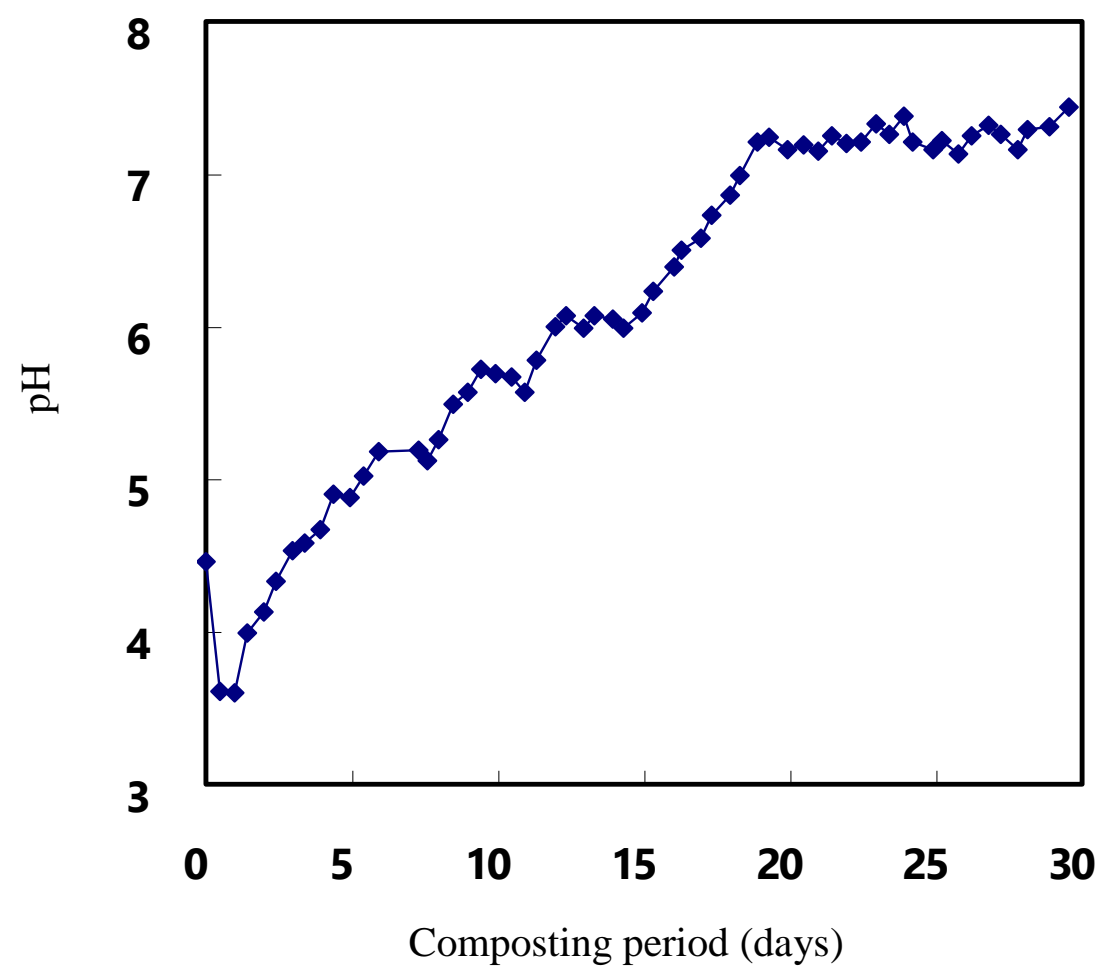

Figure 4. $\mathrm{pH}$ variation during the composting period.

\subsection{Evolution and Spatial Distribution of Temperature during the Composting Period}

Two-dimensional temperature contours of the compost pile, shown in Figure 5, were generated to better understand the temperature evolution and spatial distribution during the composting period. The temperatures are represented in different colors and vary along the width and height of the composting pile. From the figure, the average temperature was observed to steadily increase from day 1 to day 16, with the highest temperatures observed from the center of the pile. The regions of the pile near the exterior were cooler than the interior as heat dissipated into the surrounding environment. For instance, the regions with a close-to-ambient temperature $\left(35-40{ }^{\circ} \mathrm{C}\right)$ were located around the exterior on day 1 , while the highest average temperatures $\left(\sim 50^{\circ} \mathrm{C}\right)$ were observed in the center of the pile, where heat dissipation is the lowest.

In the succeeding composting days, the temperature from the center of the pile increased, while the cooler layers reduced in size. On day 5, for example, the regions $<40^{\circ} \mathrm{C}$ were much thinner and the interior average temperature was higher, ranging from $55-65^{\circ} \mathrm{C}$ compared with day 1 . This day corresponds to the end of the acclimatization period and the beginning of the thermophilic phase. Day 7-16 covered this phase which is characterized by the highest temperature in the entire composting period. The cooler regions further decreased while the hottest ones grew in size. Most of the pile had a temperature range of $70-80^{\circ} \mathrm{C}$. In this study, the thermophilic phase took roughly 15 days. By day 23 , the temperature dropped, signaling the cooling and maturation phase of the compost pile, with the latter phase reached on day 28 . The temperatures dropped, with the outer layers falling within $30-40{ }^{\circ} \mathrm{C}$, while the interior part of the pile was $<45^{\circ} \mathrm{C}$. These figures help to better understand the temperature evolution and spatial distribution during the composting process, which would be useful in heat recovery and utilization of this technology. 

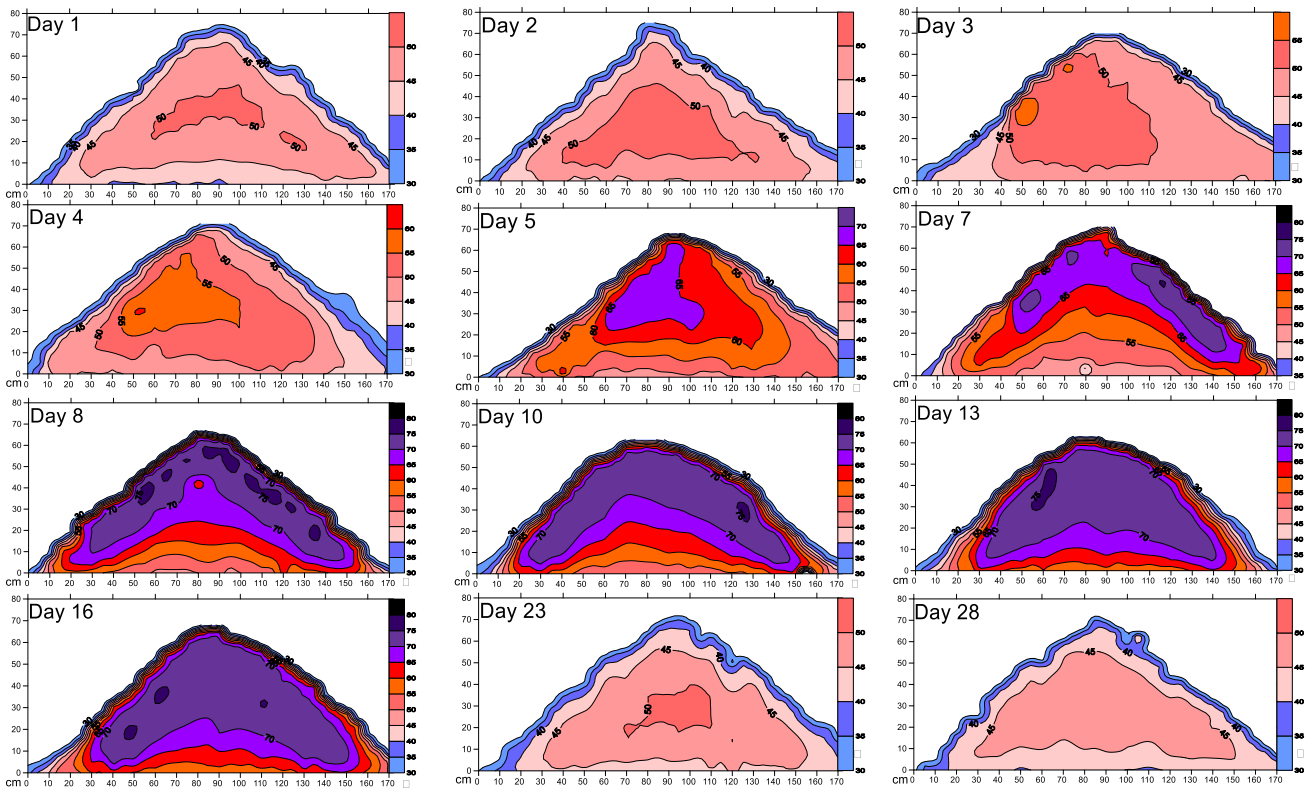

Figure 5. 2D temperature contour plots of the compost pile at different incubation days.

\subsection{Estimation of Heat Produced during the Composting Process}

The heat produced during the composting results from the aerobic microbial degradation of the organic waste. The resultant heat can be captured and applied as a bioenergy source. However, before this comes to fruition, the amount of heat that can be generated from the composting needs to be quantified. Unlike combustion, composting does not undergo full oxidation, and therefore the heat produced is relatively lower. Equation (1) was used to estimate the heat produced during our composting experiment. The equation assumes the process is at a constant pressure with a constant specific heat capacity. This is a valid assumption during composting, which has relatively small changes in pressure [38].

$$
q=m s \Delta T
$$

where $q$ is the heat $(\mathrm{kJ}), m$ is the mass $(\mathrm{kg}), s$ is the specific heat $\left(\mathrm{kJ} / \mathrm{kg}{ }^{\circ} \mathrm{C}\right)$, and $\Delta T$ is the temperature difference $\left({ }^{\circ} \mathrm{C}\right)$.

The mass was taken to be $400 \mathrm{~kg}$, the initial weight of the compost mixture, and was assumed not to vary within the 30 days. The ambient temperature was taken to be $30{ }^{\circ} \mathrm{C}$ during the entire process. The overall specific heat capacity of the compost, presented in Table 2, was estimated based on the relative amounts of the compost material and their standard specific heats. Therefore, the estimated heat produced from the compost pile in the 30 days was $1194 \mathrm{MJ}$. This equates to $2.99 \mathrm{MJ} / \mathrm{kg}$ of food waste which was higher than the heat produced from the mushroom and municipal waste composting values reported in previous studies (Table 3). However, it was lower than the values reported by [22]. This is because the heat produced during the composting depends on the energy content of the compost mixture, its biodegradability, and the prevailing composting conditions [25].

Table 2. Estimated material composition and overall specific heat for the food waste compost.

\begin{tabular}{lccc}
\hline Material & Amount Present (\%) & $s\left(\mathbf{k J} / \mathbf{k g}^{\circ} \mathbf{C}\right)$ & Overall $s$ \\
\hline Water & 65 & 4.184 \\
Sawdust & 15 & $1.4^{\mathrm{b}}$ & 3.1336 \\
Mature compost & 20 & $1.02^{\mathrm{a}, \mathrm{b}}$ & \\
\hline \multicolumn{4}{c}{}
\end{tabular}


Table 3. Comparison of heat production values during the composting process.

\begin{tabular}{lcccc}
\hline Compost Material & $\begin{array}{c}\text { Thermophilic } \\
\text { Temp }\left({ }^{\circ} \mathbf{C}\right)\end{array}$ & $\begin{array}{c}\text { Period } \\
\text { (Days) }\end{array}$ & $\begin{array}{c}\text { Heat Production } \\
(\mathbf{M J} / \mathbf{k g})\end{array}$ & Reference \\
\hline Food waste & 70 & 30 & 2.99 & This study \\
Mushroom waste & $55-63$ & - & 1.23 & {$[40]$} \\
Municipal waste & $\sim 60$ & 16 & 1.14 & {$[41]$} \\
Poultry manure & $>60$ & - & $16.83-19.70$ & {$[22]$} \\
and wood shavings & & & & \\
\hline
\end{tabular}

-: Not mentioned.

The heat produced on an hourly basis was $1659 \mathrm{~kJ} / \mathrm{hr}$. This was similar to the values of the small-scale composting systems reported by previous studies. Table 4 shows the heat production rates from the different composting scale sizes. The heat production rates increased with the increasing scale of the compost system. Besides the operational design and conditions, the amount of heat that can be produced would depend on the scale of the compost facility [25].

Table 4. Comparison of heat production rates of different compost scales.

\begin{tabular}{lcccc}
\hline \multicolumn{1}{c}{ Compost Scale } & Compost Material & Period (Days) & $\begin{array}{c}\text { Heat Production } \\
\text { Rate } \mathbf{( k J / h r )}\end{array}$ & References \\
\hline $\begin{array}{l}\text { Small-scale } \\
\left(0.6 \mathrm{~m}^{3}\right)\end{array}$ & Food waste & 30 & 1659 & This study \\
$\begin{array}{l}\text { Small-scale } \\
\left(1 \mathrm{~m}^{3}\right)\end{array}$ & Farmyard manure & - & 2304 & {$[42]$} \\
$\begin{array}{l}\text { Pilot-scale } \\
\left(1 \mathrm{~m}^{3}\right)\end{array}$ & Yard waste & 5 & 1948 & {$[43]$} \\
$\begin{array}{l}\text { Pilot-scale } \\
\left(5 \mathrm{~m}^{3)}\right.\end{array}$ & Agricultural wastes & 5 & 4023 & {$[44]$} \\
$\begin{array}{l}\text { Pilot-scale } \\
\left(5 \mathrm{~m}^{3}\right)\end{array}$ & Pig manure & 21 & 16,925 & {$[45]$} \\
$\begin{array}{l}\text { Large-scale } \\
\left(142 \mathrm{~m}^{3}\right)\end{array}$ & Agricultural wastes & - & 211,011 & {$[46]$} \\
\hline
\end{tabular}

-: Not mentioned.

This study investigated the optimal initial moisture content and seeding amount required for an effective composting. An attempt was also made to estimate the heat produced during the 30-day composting process. The study showed that the heat produced from composting can be a potential bioenergy source that can find a number of applications, including absorption refrigeration, organic Rankine cycles, and liquid-to-air heat exchangers. However, before this can be accomplished, further investigations on the heat production, capture, and application should be evaluated for different composting scales. To accurately measure the heat production, factors including the operational conditions, heat losses, and operational design should be considered. A cost-benefit analysis can also be performed to provide a comprehensive conclusion on the bioenergy potential of food waste composting.

Author Contributions: Conceptualization, C.K.Y. and C.L.; methodology, C.K.Y. and H.C.S.; validation, C.L., and N.K.C.; formal analysis, C.K.Y.; investigation, C.L.W.; resources, C.L.; data curation, C.K.Y., H.C.S. and C.L.W.; writing-original draft preparation, C.K.Y. and M.E.C.; writing-review and editing, N.K.C.; visualization, C.L.W.; supervision, C.L.; project administration, C.K.Y. All authors have read and agreed to the published version of the manuscript.

Funding: This research received no external funding.

Acknowledgments: We would like to acknowledge the assistance provided by the Center of Environmental Analysis at the National Kaohsiung University of Science and Technology.

Conflicts of Interest: The authors declare no conflict of interest. 


\section{References}

1. Parfitt, J.; Barthel, M.; Macnaughton, S. Food waste within food supply chains: Quantification and potential for change to 2050. Philos. Trans. R. Soc. B 2010, 365, 3065-3081. [CrossRef] [PubMed]

2. Van Zanten, H.H.; Mollenhorst, H.; Oonincx, D.G.; Bikker, P.; Meerburg, B.G.; de Boer, I.J. From environmental nuisance to environmental opportunity: Housefly larvae convert waste to livestock feed. J. Clean. Prod. 2015, 102, 362-369. [CrossRef]

3. Zhang, C.; Su, H.; Baeyens, J.; Tan, T. Reviewing the anaerobic digestion of food waste for biogas production. Renew. Sust. Energ. Rev. 2014, 38, 383-392. [CrossRef]

4. Sanchez-Vazquez, S.; Hailes, H.; Evans, J. Hydrophobic polymers from food waste: Resources and synthesis. Polym. Rev. 2013, 53, 627-694. [CrossRef]

5. Park, S.Y.; Lee, H.U.; Park, E.S.; Lee, S.C.; Lee, J.W.; Jeong, S.W.; Kim, C.H.; Lee, Y.C.; Huh, Y.S.; Lee, J. Photoluminescent green carbon nanodots from food-waste-derived sources: Large-scale synthesis, properties, and biomedical applications. ACS Appl. Mater. 2014, 6, 3365-3370. [CrossRef]

6. Maitan-Alfenas, G.P.; Visser, E.M.; Guimarães, V.M. Enzymatic hydrolysis of lignocellulosic biomass: Converting food waste in valuable products. Curr. Opin. Food Sci. 2015, 1, 44-49. [CrossRef]

7. Li, Z.; Lu, H.; Ren, L.; He, L. Experimental and modeling approaches for food waste composting: A review. Chemosphere 2013, 93, 1247-1257. [CrossRef]

8. Lin, C. A negative-pressure aeration system for composting food wastes. Bioresour. Technol. 2008, 99, 7651-7656. [CrossRef]

9. Nakakubo, T.; Tokai, A.; Ohno, K. Comparative assessment of technological systems for recycling sludge and food waste aimed at greenhouse gas emissions reduction and phosphorus recovery. J. Clean. Prod. 2012, 32, 157-172. [CrossRef]

10. Mao, I.F.; Tsai, C.J.; Shen, S.H.; Lin, T.F.; Chen, W.K.; Chen, M.L. Critical components of odors in evaluating the performance of food waste composting plants. Sci. Total Environ. 2006, 370, 323-329. [CrossRef]

11. Cerda, A.; Artola, A.; Font, X.; Barrena, R.; Gea, T.; Sánchez, A. Composting of food wastes: Status and challenges. Bioresour. Technol. 2018, 248, 57-67. [CrossRef] [PubMed]

12. Lin, C.; Wu, E.M.Y.; Lee, C.N.; Kuo, S.L. Multivariate statistical factor and cluster analyses for selecting food waste optimal recycling methods. Environ. Eng. Sci. 2011, 28, 349-356. [CrossRef]

13. Wong, J.; Ma, K.; Fang, K.; Cheung, C. Utilization of a manure compost for organic farming in Hong Kong. Bioresour. Technol. 1999, 67, 43-46. [CrossRef]

14. Lovell, S.T. Multifunctional urban agriculture for sustainable land use planning in the United States. Sustainability 2010, 2, 2499-2522. [CrossRef]

15. Tran, H.T.; Vu, C.T.; Lin, C.; Bui, X.T.; Huang, W.Y.; Hoang, H.G.; Liu, W.Y. Remediation of highly fuel oil-contaminated soil by food waste composting and its volatile organic compound (VOC) emission. Bioresour. Technol. Rep. 2018, 4, 145-152. [CrossRef]

16. Chang, J.I.; Chen, Y.J. Effects of bulking agents on food waste composting. Bioresour. Technol. 2010, 101, 5917-5924. [CrossRef] [PubMed]

17. Adhikari, B.K.; Barrington, S.; Martinez, J.; King, S. Effectiveness of three bulking agents for food waste composting. Waste Manag. 2009, 29, 197-203. [CrossRef]

18. Pan, I.; Dam, B.; Sen, S. Composting of common organic wastes using microbial inoculants. 3 Biotech 2012, 2, 127-134. [CrossRef]

19. Karnchanawong, S.; Nissaikla, S. Effects of microbial inoculation on composting of household organic waste using passive aeration bin. Int. J. Recy. Org. Waste Agric. 2014, 3, 113-119. [CrossRef]

20. Guo, R.; Li, G.; Jiang, T.; Schuchardt, F.; Chen, T.; Zhao, Y.; Shen, Y. Effect of aeration rate, C/N ratio and moisture content on the stability and maturity of compost. Bioresour. Technol. 2012, 112, 171-178. [CrossRef]

21. Pace, M.G.; Miller, B.E.; Farrell-Poe, K.L. The Composting Process; Utah State University: Logan, UT, USA, 1995.

22. Ahn, H.; Richard, T.; Choi, H. Mass and thermal balance during composting of a poultry manure-Wood shavings mixture at different aeration rates. Process Biochem. 2007, 42, 215-223. [CrossRef]

23. Lin, C.; Sheu, D.S.; Lin, T.C.; Kao, C.M.; Grasso, D. Thermophilic biodegradation of diesel oil in food waste composting processes without bioaugmentation. Environ. Eng. Sci. 2012, 29, 117-123. [CrossRef]

24. Sobel, A.; Muck, R. Energy in animal manures. Eng. Agric. 1983, 2, 161-176. [CrossRef] 
25. Smith, M.M.; Aber, J.D.; Rynk, R. Heat recovery from composting: A comprehensive review of system design, recovery rate, and utilization. Compost. Sci. Util. 2017, 25, S11-S22. [CrossRef]

26. Smith, M.M. Creating an Economically Viable, Closed-System, Energy-Independent Dairy Farm through the On-Farm Production of Animal Bedding and Heat Capture from an Aerated Static Pile Heat Recovery Composting Operation. Ph.D. Thesis, University of New Hampshire, Durham, NH, USA, 2016.

27. Kumar, M.; Ou, Y.L.; Lin, J.G. Co-composting of green waste and food waste at low C/N ratio. Waste Manag. 2010, 30, 602-609. [CrossRef]

28. Liu, L.; Wang, S.; Guo, X.; Zhao, T.; Zhang, B. Succession and diversity of microorganisms and their association with physicochemical properties during green waste thermophilic composting. Waste Manag. 2018, 73, 101-112. [CrossRef]

29. Jiang, T.; Schuchardt, F.; Li, G.; Guo, R.; Zhao, Y. Effect of C/N ratio, aeration rate and moisture content on ammonia and greenhouse gas emission during the composting. J. Environ. Sci. 2011, 23, 1754-1760. [CrossRef]

30. Liang, C.; Das, K.C.; McClendon, R.W. The influence of temperature and moisture contents regimes on the aerobic microbial activity of a biosolids composting blend. Bioresour. Technol. 2003, 86, 131-137. [CrossRef]

31. Mihial, D.J.; Viraraghavan, T.; Jin, Y.C. Bioremediation of petroleum-contaminated soil using composting. J. Hazard. Toxic Radioact. Waste 2006, 10, 108-115. [CrossRef]

32. Wang, X.; Pan, S.; Zhang, Z.; Lin, X.; Zhang, Y.; Chen, S. Effects of the feeding ratio of food waste on fed-batch aerobic composting and its microbial community. Bioresour. Technol. 2017, 224, 397-404. [CrossRef]

33. Yu, H.; Zeng, G.; Huang, H.; Xi, X.; Wang, R.; Huang, D.; Huang, G.; Li, J.J.B. Microbial community succession and lignocellulose degradation during agricultural waste composting. Biodegradation 2007, 18, 793-802. [CrossRef] [PubMed]

34. Mbah, B.N.; Odili, P.N. Changes in moisture retention properties of five waste materials during short-term mesophilic composting. Compost Sci. Util. 1998, 6, 67-73. [CrossRef]

35. Sundberg, C.; Jönsson, H.J.B. Process inhibition due to organic acids in fed-batch composting of food waste-influence of starting culture. Biodegradation 2005, 16, 205-213. [CrossRef] [PubMed]

36. Beck-Friis, B.; Smårs, S.; Jönsson, H.; Eklind, Y.; Kirchmann, H. Composting of source-separated household organics at different oxygen levels: Gaining an understanding of the emission dynamics. Compost Sci. Util. 2003, 11, 41-50. [CrossRef]

37. Cheung, H.; Huang, G.; Yu, H. Microbial-growth inhibition during composting of food waste: Effects of organic acids. Bioresour. Technol. 2010, 101, 5925-5934. [CrossRef] [PubMed]

38. Irvine, G.; Lamont, E.; Antizar-Ladislao, B. Energy from waste: Reuse of compost heat as a source of renewable energy. Int. J. Chem. Eng. 2010, 2010. [CrossRef]

39. Ahn, H.; Sauer, T.; Richard, T.L.; Glanville, T.D. Determination of thermal properties of composting bulking materials. Bioresour. Technol. 2009, 100, 3974-3981. [CrossRef]

40. Harper, E.; Miller, F.; Macauley, B. Physical management and interpretation of an environmentally controlled composting ecosystem. Aust. J. Exp. Agric. 1992, 32, 657-667. [CrossRef]

41. Klejment, E.; Rosiński, M. Testing of thermal properties of compost from municipal waste with a view to using it as a renewable, low temperature heat source. Bioresour. Technol. 2008, 99, 8850-8855. [CrossRef]

42. Vemmelund, N.; Berthelsen, L. A note on heat recovery from mechanically aerated farm-yard manure. Agric. Wastes 1979, 1, 157-160. [CrossRef]

43. Jaccard, L.; Lehmann, P.; Civilini, M.; Bertoldi, M.d. Yard waste composting with heat recovery. Compos. Sci. Util. 1993, 1, 10-14. [CrossRef]

44. Alwell, A. Innovative system uses composting process to heat high tunnel. Org. Broadcast. 2014, 22, 5.

45. Thostrup, P. Heat Recovery from Composting Solid Manure. In Proceedings of the Bioenergy 84, Göteborg, Sweden, 15-21 June 1984; pp. 217-225.

46. Tucker, M.F. Extracting thermal energy from composting. BioCycle 2006, 47, 38.

(C) 2020 by the authors. Licensee MDPI, Basel, Switzerland. This article is an open access article distributed under the terms and conditions of the Creative Commons Attribution (CC BY) license (http://creativecommons.org/licenses/by/4.0/). 